\title{
Transformaciones en el Tercer Sector: el caso de las radios comunitarias en España
}

Javier García García

Red de Medios Comunitarios

\section{Palabras clave}

Radios comunitarias, tercer sector, España, emisoras sin ánimo de lucro, emisoras libres, Internet

\section{Resumen}

Tradicionalmente los medios de comunicación han sido un espacio acaparado por los gobiernos y las empresas. Pero al marguen de estos grandes medios la ciudadanía ha buscado sus propios espacios de expresión. La ciudadanía no quiere limitarse a ser un mero consumidor y ha ido creando sus propios medios de comunicación como publicaciones, radios o televisiones. Esta participación ciudadana ha cobrado especial intensidad en las últimas décadas con la aparición de Internet, pero nos encontramos con multitud de experiencias previas que ya venían apuntando cuales eran las necesidades de comunicación de los distintos grupos sociales.

Una de las experiencias que nos encontramos son las llamadas radios libres y comunitarias, cuya historia corre de forma paralela a la historia de la democracia española. Con la llegada de los nuevos medios de comunicación estas emisoras son vistas como una reliquia del pasado que ha quedado superada por las posibilidades que Internet ofrece a la ciudadanía para crear sus propios medios de comunicación.

El presente texto se aborda la problemática legal del Tercer sector audiovisual y se analiza la el caso de las radios libres y comunitarias en España, en espacial se pone el foco en la relación de estas emisoras con Internet y las redes sociales. El artículo apunta al carácter poco democrático que ha caracterizado las políticas de comunicación en España lo que ha impedido el desarrollo de un Tercer Sector Audiovisual y plantea algunos retos e incógnitas para el futuro de las radios comunitarias. 

Transformations in the Third Sector: the case study of the community radios
in Spain

\title{
Keywords
}

Community radios, Third Sector, Spain, non profit radios, free radios, Internet

\begin{abstract}
The media has been traditionally a space taken by goverments and private businesses. But at the same time, and despite of the existence of this kind of mainstream media, the citizens have been looking for their own spaces of expression and freedom of broadcasting. They don't want to be only a recipient or consumer of information and all throughout years they have founded lots of social media as publications, as radios, as televisions. This participation of the people has been grown exponentially in last decades because of the birth of Internet, altought we can found dozens of previous alternative experiences and projects which worked in the needs of social communication and different social groups.

One of that experiences before Internet is the case of free and community radio which history was developed at the same time that the spanish democracy. Nowadays, the rise of new media has consigned community radio to oblivion, like an old relic from the past. It has been beaten for the possibilities that Internet provides to the citizens to create their own ways for communication.

This paper deals with the legal issues of Third Media Sector and it analyzes the case of free and community media in Spain, above everything the links between this experiences with Internet and social networks. As a conclusion, the communication policies in Spain have been always poorly democratic, and this fact has blocked the development of the Third Media Sector in this country. Finally, this paper suggests some challenges and open questions for the future of community radios.
\end{abstract}

\begin{abstract}
Autor
Javier García García [javgarci@ucm.es] es experto en Gestión de Organizaciones no Lucrativas y cuenta con una amplia trayectoria en el campo de la radiodifusión comunitaria. Desde 1995 es integrante de la Asociación Radio Almenara, participa en la Unión de Radios Libres y Comunitarias de Madrid (URCM) y en el grupo de trabajo Derecho a la Comunicación de la Red de Medios Comunitarios (ReMC).
\end{abstract}




\section{Introducción}

La muerte de Franco en 1975 y la entrada en vigor de la nueva Constitución a fines de 1978 supusieron un importante cambio respecto de los medios de comunicación tras 40 años de censura y restricciones al ejercicio de derechos fundamentales.

En aquellos años, entre radios públicas y comerciales en Frecuencia Modulada no llegaban a un centenar en todo el país y el gobierno de la UCD prepara una nueva regulación y el reparto de 300 nuevas emisoras.

Paralelamente y al margen de la normativa aparecen un gran número de emisoras que carecían de permiso para emitir y que respondían a la necesidad de expresión de distintos sectores y colectivos sociales. Este fenómeno de «radios piratas» comprendía proyectos de diverso tipo: experimentales, comerciales independientes, municipales y diversos sectores interesados en desarrollar la radio como un espacio de expresión social, cultural o educativo.

Entre esa diversidad de emisoras comenzó a desarrollarse un movimiento de radios gestionadas de forma colectiva y sin ánimo de lucro por organizaciones sociales, que reivindicaban un espacio en el dial (libertad de emisión) para ejercer la libre expresión y abrir los micrófonos a la gente:

«después del franquismo y con la recuperación de las libertades democráticas se manifiesta una voluntad, podríamos decir incluso un placer, para el ejercicio de la libertad de expresión y comunicación» (Moragas, 1988: 92).

Su referente era el movimiento que había surgido unos años antes en Francia e Italia con el nombre de radios libres (Bassets, 1981).

El reparto de aquellas 300 emisoras de radio (BOE, 1987a), así como los repartos posteriores de finales de los 80 y de los 90 , se destinaron fundamentalmente a emisoras comerciales y sirvió para consolidar las cadenas de radio existentes o propiciar la creación de nuevos grupos empresariales como Onda Cero. Los gobiernos también aseguraron frecuencias para que tanto los gobiernos autonómicos como los ayuntamientos pudieran crear sus propias emisoras.

Y así fueron repartiendo el dial dejado fuera a otro tipo de emisoras, no sólo a las radios libres y comunitarias de perfil más díscolo, también las radios escolares y a las radios universitarias han sido excluidas de los repartos de frecuencias, por lo que durante todo este tiempo estas emisoras han funcionado al margen de las regulaciones.

Con el nuevo siglo llegaron nuevas formas de emisión para la radio como la Radio Digital y la radio por Internet que han abierto nuevos espacios de difusión.

En el presente artículo, dentro de la variedad de emisoras que conforman un Tercer Sector Audiovisual, analizaremos el caso de las radios libres y comunitarias al tratarse de un tipo de radiodifusión con dilatada trayectoria. 


\section{Emisoras sin ánimo de lucro, tercer sector y radios comunitarias}

Existe cierta dificultad a la hora de definir y clasificar la heterogeneidad de emisoras de radio. Esto ha propiciado la proliferación de diversos términos según se consideren unos u otros elementos, entre los que podemos citar:

- Forma de explotación (comercial o no lucrativa)

- El tipo de entidad titular de la emisora (publica, privada, escolar, universitaria, asociativa)

- Situación legal: si cuentan o no con licencia (legales, ilegales, alegales, piratas)

- Tipo de contenidos (radio convencional, alternativa, cultural, educativa, religiosa, experimental, etc)

- El ámbito de cobertura (radios de proximidad, comarcal, nacional)

- Otros aspectos como la forma de gestión, finalidad de la emisora, su dependencia/independencia de una estructura, etc.

Según optemos por clasificar en función de uno o más elementos nos permitirá clasificar las emisoras de forma más genérica o de forma más detallada.

Si optamos por diferenciar entre emisoras con o sin ánimo de lucro, o en función de sus contenidos (programación local) podremos fácilmente confundir entre emisoras públicas (radios municipales, escolares) y emisoras de entidades privadas (asociaciones). Si optamos por fijarnos en su situación legal podemos confundir entre radios comerciales y radios comunitarias al carecer ambas de licencia.

Estas dificultades de clasificación de diferencias entre lo público, lo privado, lo lucrativo y lo no lucrativo se dan en otros sectores. En las sociedades actuales está cada vez más extendida la clasificación en tres grandes sectores: el Sector Público, el Sector Privado Mercantil, y el Sector Privado no Lucrativo o Tercer Sector. Esta caracterización permite diferenciar entre la actividad no lucrativa realizada por el sector público del privado a la vez que se distingue 2 tipos entidades privadas. Sin embargo esta clasificación, surgida de una doble negación (no público y no lucrativo), convierte al tercer sector (en sus distintos ámbitos) en un espacio excesivamente heterogéneo formado por actividades con más elementos diferenciales que comunes.

Por eso, muchas radios no se sienten reflejadas en la denominación de Tercer Sector Audiovisual porque no recoge sus especificidades y las agrupa con otras emisoras de las que se sienten muy distintas. Por otra parte nos encontramos con experiencias que tienen un difícil encaje dentro de esta forma de clasificar, como podría ser el caso de las «emisoras universitarias», que en algunos casos son promovidas por universidades públicas (primer sector), en otros son centros privados (segundo sector) y en otro caso la emisora es gestionada por 
asociaciones vinculadas a la universidad (tercer Sector). Respecto a las radios religiosas también surgen dudas sobre en qué sector ubicarlas.

Dentro del ámbito académico, resulta una cuestión en discusión. Downing (2009), que ha analizado la postura de distintos autores, opina que Tercer Sector «es un término conveniente para discusiones sobre la política de la comunicación, pero aparte de eso, no nos ofrece nada». Este autor prefiere referirse a «medios de movimientos sociales» e incluso propone junto con Pajnik la denominación de «Nanomedios de comunicación» para referirse a los medios en escala pequeña destacando su enorme impacto poniendo ante el supuesto poder de los grandes medios de comunicación (Downing, 2009).

A nivel internacional, el concepto más extendido es el de radio comunitaria. Este término está siendo utilizado por distintos organismos internacionales como la ONU, UNESCO, el Parlamento Europeo y el Consejo de Europa) bajo la influencia de entidades que como el Community Media Forum Europe (www. cmfe.eu) y la Asociación Mundial de Radios Co munitarias (www.amarc.org), referente a nivel internacional que agrupa cerca de 4.000 miembros y asociados en más de 130 países.

AMARC define a las emisoras comunitarias como «actores privados que tienen una finalidad social y se caracterizan por ser gestionadas por organizaciones sociales de diverso tipo sin fines de lucro. Su característica fundamental es la participación de la comunidad tanto en la propiedad del medio, como en la programación, administración, operación, financiamiento y evaluación. Se trata de medios independientes y no gubernamentales, que no realizan proselitismo religioso ni son de propiedad o están controlados o vinculados a partidos políticos o empresas comerciales» (AMARC, 2010).

En Europa ha estado muy extendido el término de «radio libre» aunque con el tiempo se ha ido incorporando el de radio comunitaria. Según Lewis (2007), «libre» se refiere a libertad (de emisión) frente a la regulación y frente al monopolio ejercido por los Estados en la radiodifusión en países como Italia, Francia, Bélgica. En España dicho término está muy extendido llegándose a establecer una definición en el llamado «Manifiesto de Villaverde» que es firmado por los asistentes al VI Encuentro Estatal de Radios Libres, que se celebra en este barrio de Madrid en 1983. Según Martínez (1998), la definición de las radios libres articulada en 5 puntos:

\footnotetext{
«1/ su carácter no profesional ni lucrativo; 2/ su funcionamiento autogestionario con toma directa de decisiones; 3 / su autonomía frente a grupos políticos, económicos y publicitarios; 4/ su participación al servicio de la comunidad local; 5/ su lucha contra el monopolio y centralización de la comunicación”»
}

En España existe cierta controversia entre las propias emisoras respecto al uso de los términos de «radio libre» y «radio comunitaria». Hay radios que utilizan indistintamente ambos términos para definirse mientras otras emisoras entienden que son 2 tipologías diferentes. En el presente artículo se ha optado por analizarlas de forma conjunta como un tipo de práctica dentro del Tercer Sector de la comunicación. 


\section{Los medios sin ánimo de lucro en las ondas radiofónicas}

\subsection{Radios «sin papeles»}

En España es sorprendente el elevado número de emisoras en FM que funciona sin licencia (ver tabla 1). La mayoría de estas radios se corresponde con pequeñas emisoras comerciales de carácter local e independiente de las grandes cadenas. El segundo grupo más numeroso está formado por las radios religiosas como las emisoras de la Iglesia Evangélica o como Radio María que cuenta más de un centenar de postes de emisión. Pero entre las emisoras sin licencia también encontramos que las grandes cadenas de radio recurren al uso de puntos de emisión sin licencia en zonas donde carecen de cobertura.

Tabla 1: estimación de emisoras FM existentes en España en 2011

\begin{tabular}{|l|l|l|}
\hline Total Radios en FM & Radios con licencia & Radios sin licencia \\
\hline 6.582 & 3.747 & 2.835 \\
\hline
\end{tabular}

Fuente: elaboración propia con datos de la Secretaría de Estado de Telecomunicaciones y para la Sociedad de la Información (SETSI) y «La Lista de la FM» (www.lalistadelafm.com).

Con los datos de que disponemos, podría estimarse que entre 200 y 300 emisoras de estas 2.835 radios sin licencia se corresponde con radios libres y comunitarias, emisoras educativas y universitarias y otras de tipo cultural o social (alrededor de un 10\%) que podemos distribuir de la siguiente forma:

- Al menos un centenar de radios libres y comunitarias.

- Una veintena de radios universitarias, un sector que se ha tenido un importante desarrollado en los últimos años, como muestra la creación de la Asociación de Radios Universitarias (ARU).

- Un número oscilante de pequeñas emisoras escolares. Por lo general se trata de proyectos de muy pequeña cobertura y de funcionamiento irregular o efímero por lo que resulta imposible cuantificar su número.

- Otras emisoras de difícil cuantificación (de carácter social o cultural, radios en centros penitenciarios, otros no clasificables).

\subsection{El reparto de licencias de frecuencia modulada}

Según los datos de la Secretaría de Estado de Telecomunicaciones y para la Sociedad de la Información (SETSI) hasta el momento se han planificado un total de 4.468 frecuencias para emisoras de radio en FM, de las cuales 2.564 se han destinado a emisoras de titularidad pública y 1.904 de titularidad privada. Las frecuencias para radio privada se han ido repartiendo en varias tantas, en 1979 se planificaron 300 que se sumaron a las 89 previamente existentes, en 1989 
fueron 300, en 1997 se asignaron a las CC.AA. 350 más y en 2006 se planificaron las últimas 866 frecuencias.

Hay algunas oscilaciones en las cifras porque algunas Comunidades Autónomas no han adjudicado las todas las frecuencias que les fueron asignadas.

Tabla 2: Distribución frecuencias públicas y privadas de radio en España

\begin{tabular}{|l|l|l|l|l|l|l|}
\hline & \multicolumn{3}{|l|}{ Publicas: 2.564 frecuencias } & \multicolumn{3}{l|}{ Privadas: 1.904 frecuencias (estimación) } \\
\hline & RNE & Autonómicas & Municipales & Comerciales & No comerciales & $\begin{array}{l}\text { En proceso de } \\
\text { asignación }\end{array}$ \\
\hline Total número & 691 & 717 & 1156 & 1427 & 18 & 459 \\
\hline
\end{tabular}

Fuente: elaboración propia a partir de datos de 2011 de la Secretaría de Estado de Telecomunicaciones y para la Sociedad de la Información (SETSI).

De las 1.904 frecuencias destinadas a radio privada sólo 17 se han destinado a emisoras no comerciales, lo que representa un $0,9 \%$ del total de las frecuencias privadas y un $0,4 \%$ del total de frecuencias disponibles. Dentro de estas 17 licencias nos encontramos la siguiente tipología:

- 5 emisoras educativas que corresponde a licencias obtenidas en Canarias y Galicia por la Fundación Radio ECCA (www.radioecca.org).

- Respecto a las emisoras de contenido religioso la Fundació Missatge Humà i Cristià Ràdio Estel (www.radioestel.com) ha obtenido 6 licencias en Cataluña y la Asociación Radio Maria (www.radiomaria.es) 1 en Madrid.

- 4 licencias corresponden a emisoras de entidades sin ánimo de lucro y desarrollan una programación de tipo local o cultural.

- Tan sólo 2 licencias se han destinado a lo que hemos denominado «radios comunitarias» lo que representa el $0,04 \%$ del total de frecuencias disponibles. Se trata de Radio Klara de Valencia, que obtuvo una concesión de «emisora cultural» en la única convocatoria en la que se ha diferenciado entre emisoras comerciales y emisoras no comerciales (DOGV, 1989) y Xorroxin Irratia, que obtuvo una concesión en la localidad de Lesaka (Navarra) en 1998 en un concurso en que tuvo que competir con empresas.

\subsection{Las radios sin ánimo de lucro en la legislación española}

España es un claro ejemplo de discriminación hacia las llamadas emisoras comunitarias, a través de marcos regulatorios que impiden en la práctica el acceso de frecuencias a entidades no lucrativas.

Contrariamente al pensamiento generalizado (incluso entre las propias radios sin ánimo de lucro) la legislación siempre ha previsto que entidades sin ánimo de lucro puedan acceder a frecuencias (BOE, 1979; BOE, 1987b). Más que un 
problema legal, lo que encontramos es una falta de voluntad política. Tanto en el caso de la radio como el de la Televisión las distintas administraciones han preferido repartir las licencias entre medios públicas (RNE, autonómicas y municipales) y a medios privados.

El Real Decreto 1433/1979 que establece el Plan Técnico Transitorio del Servicio Público de Radiodifusión Sonora en Frecuencia Modulada ya recogía la existencia tanto de emisoras comerciales como de emisoras institucionales y educativas. En su Artículo $7^{\circ}$ establecía que «El Gobierno (...) podrá otorgar concesiones de emisoras educativas y culturales a favor de la instituciones o entidades públicas o privadas legalmente constituidas que, sin fines lucrativos... " (BOE, 1979). Una redacción muy similar fue incorporada por varias CC.AA. En sus primeros decretos de radiodifusión (Cataluña, País Vasco, Andalucía, Galicia y País Valenciano).

En 1987 se aprueba Ley de Ordenación de las Telecomunicaciones, LOT (BOE, 1987b) que se refiere a la radio privada como «gestión indirecta mediante concesión administrativa a través personas físicas o jurídicas» indicando que las entidades sin ánimo de lucro podían optar a frecuencias. Llama la atención que en el Proyecto de Ley elaborado inicialmente por el gobierno se distinguía entre explotación comercial y cultural en FM (en AM sólo comercial): «Corporaciones Locales, personas físicas o jurídicas para su explotación comercial o con fines culturales». El Ministro de Cultura reconoció haber mantenido reuniones con la Asociación Nacional de Radios Privadas (ANRP) (BOCG, 1987c), por lo que cabe pensar que las radios comerciales presionaron para eliminar los «fines culturales» de la ley.

En la década de los 90, una vez concluido en traspaso de competencias en materia de concesión de emisoras, la mayoría de las CC.AA. establecieron en sus decretos dos categorías diferenciadas dentro de la "gestión indirecta» (entidades privadas): las «radios comerciales» y las «radios culturales sin ánimo de lucro» emitir publicidad pero si patrocinio. En algunos casos se indicaba que su cobertura sería restringida (Castilla y la Mancha, Andalucía, Cataluña, La Rioja) pero en otros no (Madrid, Murcia, Extremadura, Castilla y León, Baleares, País Vasco, Galicia, Valencia). Navarra y Asturias sólo se referían a personas jurídicas en general; Canarias, Aragón y Cantabria sólo reconocieron la posibilidad de emisoras comerciales.

Durante finales de los 90 se repartieron cerca de 300 frecuencias, sin embargo, ninguna CC.AA. reservó frecuencias para emisoras culturales o sin ánimo de lucro con la excusa de que no podían destinar frecuencias a una tipología de emisoras que la planificación estatal no reconocía. Sin embargo la Administración Central ha indicado que al ser una competencia de las CC.AA. no era necesario tal reconocimiento en la normativa estatal (BOCG, 1998; BOCG, 2007).

En 2004, los socialistas vuelven al gobierno. Entre sus promesas electorales se cuentan la aprobación de una Ley Audiovisual, la creación de un organismo 
audiovisual independiente y una ley para la radiotelevisión Pública. En 2005 el nuevo Gobierno aprueba un Anteproyecto de Ley Audiovisual en el que incluye los servicios de difusión comunitarios y servicios de difusión de proximidad. Pero la tramitación de esta ley fue paralizada ante las presiones de los medios privados. Paralelamente en Cataluña se aprobaba una Ley Audiovisual que dedicaba su capítulo VI a los servicios de comunicación audiovisual sin ánimo de lucro dando cabida a emisoras comunitarias y a emisoras universitarias. La Ley establece una reserva de espacio público de comunicación para este tipo de servicios y prevé medias de fomento e incluyo la posibilidad de recibir ayudas a través de una tasa a los medios comerciales, pero estas medidas aún se han aplicado. Estos hitos legislativos están muy relacionados con la labor desarrollada desde las emisoras comunitarias, como la Assemblea per la comunicació social (www.latele.cat) a nivel catalán y la Red de Medios Comunitarios (ReMC) a nivel estatal.

En la segunda legislatura de Zapatero (2008) se retoma la Ley Audiovisual pero con un enfoque distinto al previsto en 2005, por lo que algunos autores se refieren a "giro neoliberal» (Zallo, 2010) o «Ley UTECA» (Meda, 2010). A pesar de los cambios el nuevo Proyecto de Ley mantiene en uno de sus artículo el reconocimiento de los «servicios de comunicación audiovisual comunitarios no comerciales» a los que se les impone restricciones respecto a su forma de financiación y gestión. Del Anteproyecto de ley de 2005 se conserva únicamente la definición «las entidades privadas que tengan la consideración legal de entidades sin ánimo de lucro podrán prestar servicios de comunicación audiovisual comunitarios sin ánimo de lucro para atender las necesidades sociales, culturales y de comunicación específicas de comunidades y grupos sociales, así como para fomentar la participación ciudadana y la vertebración del tejido asociativo» (BOE, 2010).

Ley General Audiovisual llega al Congreso en octubre de 2009, se tramita por procedimiento de urgencia y es aprobada en marzo de 2010. Al texto se le realizan algunos cambios, respecto de los cuales la ReMC tuvo una participación activa al conseguir introducir algunas de sus propuestas a través de grupos parlamentarios (IV-IC, ERC, BNG), a saber:

- El artículo 4 incorpora que «todas las personas tienen el derecho a que la comunicación audiovisual se preste a través de una pluralidad de medios, tanto públicos, comerciales como comunitarios».

- Y al artículo 32 se incorpora una reserva de espectro para estos medios: «la Administración General del Estado debe garantizar en todo caso la disponibilidad del dominio público radioeléctrico necesario para la prestación de estos servicios» así como la intransferibilidad de las licencias comunitarias: «No podrá ser objeto de transmisión ni arrendamiento».

- Se consigue introducir un disposición destinada a regular a los medios existentes que operaban sin licencia, pero su redacción final es confusa (disposición transitoria decimocuarta). 
Cómo aspectos negativos, la ley ha mantenido la prohibición de emitir publicidad o patrocinio, además de la necesidad de autorización para que sus gastos de explotación anuales superen los 100.000 euros en el caso TV y de 50.000 euros en el caso de los servicios de radio. Llama la atención que en la ley no se recoge ninguna mención respecto de la cobertura de estas emisoras. Tampoco se recoge la prestación de servicios de comunicación por parte de universidades o centros educativos que podrían encontrarse con dificultades para ser consideradas como servicios de comunicación comunitarios porque la ley se refiere exclusivamente a entidades privadas.

Tras la aprobación de la ley, la mayor parte de CC.AA. ha procedido a modificar su normativa incluyendo un apartado destinado a «los servicios de comunicación audiovisual sin ánimo de lucro». Si atendemos a su contenido literal o a los decretos autonómicos podríamos pensar que la problemática legal de estas emisoras ha quedado resulta y que es previsible que los cambios legales propicien el desarrollo del Tercer Sector Audiovisual. Pero si atendemos al desarrollo que ha tenido la Ley observamos que vamos en el camino contrario.

\subsection{Ley General de Comunicación Audiovisual y sus incumplimientos}

Sorprendentemente, la aprobación de la esperada Ley General de la Comunicación Audiovisual no ha supuesto ninguna mejora a la situación legal de los medios comunitarios. Incluso podríamos decir que la situación ha empeorando porque se han seguido repartiendo licencias de radio y televisión en las que se excluye a las emisoras no comerciales. Al irse completando el dial con nuevas adjudicaciones de emisoras va quedando menos espacio para las emisoras que funcionan sin licencia que pugnan por los huecos libres en el dial. En algunas ciudades la situación es insostenible, sobre todo para las emisoras más pequeñas.

La justificación de las CC.AA. es que la Administración General del Estado no ha procedido a planificar el «dominio público radioeléctrico necesario para la prestación de estos servicios» tal como establece el artículo 32 de la ley. Por su parte el Gobierno estatal se justifica diciendo que la regulación de los servicios de comunicación comunitarios está en fase de tramitación.

Pero lo cierto es que la Secretaria de Estado de Telecomunicaciones y para la Sociedad de la Información (SETSI) cuenta desde hace tiempo con un proyecto de reglamento para los servicios de comunicación comunitarios (MITYC, 2010). El texto fue presentado en el Consejo Asesor de las Telecomunicaciones y para la Sociedad de la Información (CATSI) celebrado en noviembre de 2010. La Red de Medios Comunitarios (ReMC) se mostró contraria al contenido de los reglamentos y recabó apoyo de distintas organizaciones sociales para presentar alegaciones. 
El proyecto de reglamento establecía que las emisoras de radio y TV comunitarias contarían con un potencia muy reducida de emisión (máximo 8 watios) y en ciudades de más de 100.000 habitantes su cobertura no podría superar el $20 \%$ de la localidad. Estas restricciones eran de aplicación tanto a servicios de TV como de radio tanto en FM como en digital. El argumento fundamental de la SETSI era la falta de espectro radioeléctrico y sólo estaba dispuesta a realizar ligeras modificaciones, como el aumento de la potencia de 8 a 25 watios). Para la ReMC, se trataba de una reglamentación discriminatoria, contraria a la propia Ley Audiovisual que supone condenar a los medios comunitarios a la marginalidad e incluso impide acceder a las licencias que las CC.AA. aún no habían repartido. Por otra parte, la ReMC proponía la asignación de autorizaciones a las emisoras pre-existentes a la Ley en base a lo dispuesto en la Disposición transitoria decimocuarta (BOE, 2010). Pero la confusa redacción de la disposición ha sido aprovechada por la SETSI para interpretarla de forma restrictiva, dando amparo únicamente a las televisiones comunitarias existentes desde 1995.

Finalmente el proyecto de reglamento queda paralizado, al igual que ha sucedido con otros intentos de regular los medios no comerciales, y todo parece indicar que el actual gobierno ha optado por seguir incumpliendo lo dispuesto en la Ley (reserva de espectro radioeléctrico para tercer sector).

La ReMC ha iniciado algunas líneas de acción legal ante el Gobierno estatal y las CC.AA. En Canarias y en Galicia se han impugnado ante los tribunales las convocatorias de concurso para adjudicación de emisoras de radio. Por otra parte algunas radios como Radio Iris 7 (Castilla y león), Cuac FM (Coruña) y Tas-Tas Irratia (Bilbao), han optado presentarse a los concursos convocados aunque estos concursos están destinados a emisoras comerciales. Habrá que esperar los resultados de estas acciones.

\subsection{La radio digital por ondas ¿una posible solución?}

La radio digital comenzó a implantarse en España en 1999 con la aprobación del primer Plan Técnico de Radiodifusión Digital Terrestre (Real Decreto 1287/1999, de 23 de julio) Se han otorgado licencias de Radio digital DAB y DRM de ámbito estatal y se han planificado frecuencias de radio DAB para que sean adjudicadas por las CC.AA. (Real Decreto 776/2006, de 23 de junio).

Sin embargo la radio digital en España está atascada, las emisoras que emiten lo hacen de forma testimonial con el objetivo de no perder las licencias obtenidas. Y muchas de las frecuencias planificadas ni siquiera han sido adjudicadas por las CC.AA.

En estos momentos existe una gran incertidumbre respecto al futuro de la radio digital terrestre. A diferencia de lo ocurrido con la TDT no existe un plan de implantación de la radio digital a nivel europeo ni una decisión definitiva sobre 
el estándar a utilizar, lo que ha propiciado que muy pocos países hayan apostado por su desarrollo (Francia es una de las excepciones).

Recientemente el Gobierno aprobó un plan técnico de digitalización integral del servicio de radiodifusión sonora terrestre y modificó el Plan Técnico en cumplimiento de lo dispuesto en la disposición transitoria decimoquinta de la Ley 7/2010 (BOE 2010). Sin embargo dichas medidas consistían en parches técnicos que mostraban que el Gobierno no tiene ningún plan para la Radio Digital. Y con el actual contexto de crisis no parece a corto plazo la situación cambie.

\section{Evolución de las radios libres y comunitarias}

\subsection{El origen de las radios comunitarias en España}

A finales de la década de 1970, tras el final de la dictadura franquista y bajo la influencia de la experiencia de las radios libres en Italia y Francia, nacieron las primeras experiencias de radios comunitarias en España. Se trata de emisoras independientes de grupos políticos, empresariales o económicos cuya gestión y programación se elabora de forma colectiva, promovidas por un grupo de personas o por una asociación sin ánimo de lucro, siendo un fenómeno eminentemente urbano. Durante la década de 1980 nacieron una gran cantidad de radios con estas características en multitud de localidades. Desde entonces, algunos de estos proyectos de comunicación han desaparecido a la vez que han surgido otros nuevos, alternándose épocas de mayor y menor actividad.

Los años 80 suponen su época de mayor influencia, adquieren mucha popularidad. Las radios libres jugaron un rol importante en la animación de la campaña y creación del debate contra la integración española en la OTAN, por eso el triunfo del Sí en el referéndum de 1986 va a significar un revés (Serrano, 1994). Al mismo tiempo, los encuentros estatales van dando cuenta de las dificultades de coordinación de un movimiento heterogéneo y fragmentado. El movimiento empieza a perder fuerza y presencia pública al igual que sucede con otros movimientos sociales del período (Martínez, 1998).

La década de los 90 va a significar una etapa de recambio y reinvención. Muchos proyectos han ido desapareciendo pero surgen otros nuevos, muchos de los cuales existen hasta hoy (Radio Enlace, Radio Almenara, Tas Tas Irratia, Radio Contrabanda, Radio Topo, Cuac FM, etc) y algunas emisoras ya existentes en los 80 se renuevan y adquieren nueva fuerza. El término «radios libres» empieza a conjugarse con el concepto de «radios comunitarias». Las administraciones dejan funcionar a estas emisoras. Los cierres y multas de la década anterior dan paso a una permisividad tácita, pero carente del reconocimiento legal y por tanto, de alta precariedad. 


\subsection{Tomando impulso}

Los hitos sociales, tecnológicos y comunicativos del cambio de siglo y la emergencia del movimiento antiglobalización en Seattle (1999) también van a repercutir a nivel español, de manera que surgen movilizaciones de la sociedad civil y hay una reactivación de los movimientos sociales. Con respecto a las radios nos encontramos un resurgir de los espacios de encuentro e intercambio entre las radios y se comienzan a sentar las bases que facilitarán la creación de un espacio de coordinación y una vuelta a la pelea por el reconocimiento legal (Calle, 2005). Así, a partir del año 2003 se retoman los encuentros anuales de radios lo que propicia la creación en 2005 de la Red de Medios Comunitarios (ReMC) como un espacio que aglutina a radios, televisiones y proyectos de información alternativa. Desde entonces la ReMC ha promovido varios encuentros de medios alternativos Salamanca (2006), Toledo (2006) y Bilbao (2007), Barcelona (2009), Alicante (2010) y Asturias (2012) que han contribuido a una mayor coordinación entre los medios, intercambio de programas y de conocimientos. Uno de los aspectos donde más se ha incidido es el de defensa legal y derecho a la comunicación.

Un destacable sector de las radios libres se ha mantenido al margen de la ReMC y estableciendo sus propias redes de coordinación y diferentes estrategias para enfrentar abordar la problemática legal, como es el caso de la Federación Aragonesa de Radios Libres o la Coordinadora Ràdios Lliures de Catalunya.

A pesar del importante trabajo desarrollado por las radios libres y comunitarias no han podido recuperar la incidencia y popularidad que lograron en los años 80. Tampoco han logrado resolver su situación legal ni garantizar su espacio en el dial, cada vez más privatizado. Sin embargo han conseguido grandes avances respecto a su coordinación, su producción y su conexión con los movimientos sociales.

\subsection{Nuevo escenario, la crisis y el $15 \mathrm{M}$}

La crisis económica ha causado un fuerte impacto tanto en el sector audiovisual como en el Tercer Sector. Fusiones entre cadenas TV, despidos masivos en los medios públicos y privados, desaparición de emisoras municipales, drásticos recortes de las ayudas a ONGs y entidades sin ánimo de lucro. Sin embargo la crisis no supone una gran amenaza al maltrecho Tercer Sector Audiovisual, ya acostumbrado a sobrevivir entre constantes dificultades (legales y económicas). Las radios afectadas han sido las que cuentan con personal contratado y realizan proyectos sociales financiados por subvenciones públicas. Los drásticos recortes están obligando a estas radios a reorganizarse, por el momento no se tiene constancia de la desaparición de ninguna radio.

El sustento fundamental de las radios libres y comunitarias lo constituye la participación activista, esto, unido a un austero funcionamiento y sus tradicionales 
formas de autofinanciación (como las cuotas que aportan participantes de la radio), suponen la garantía de continuidad de este tipo de radios.

Mucho más significativo resulta el impacto del nuevo ciclo de movilizaciones. 2011 supone un punto de inflexión para los movimientos sociales, la gran ola producida a partir de del 15 de marzo de 2011 trae consigo un aumento de las protestas sociales (en forma de mareas) y el surgimiento de nuevos espacios y referentes de organización ciudadana. El efecto que esto ha tenido en las organizaciones sociales preexistentes al 15M ha sido desigual, para unas organizaciones ha supuesto un nuevo impulso pero otras sin embargo no se han beneficiado del aumento de la participación o incluso están en fase de declive.

Estamos, por tanto, ante un proceso de recambio y reconfiguración en los movimientos sociales y en sus formas de mediactivismo. Las protestas de 2011 y 2012, tanto en España como a nivel internacional, han hecho emerger nuevas prácticas de comunicación ciudadana ligadas a las nuevas tecnologías y las redes sociales (inmediatez, distribución viral). Los nuevos dispositivos portátiles (smartphones y tablets) han multiplicado el uso del streaming de video (Youtube, Bambuser o Livestream) para retransmitir en directo y documentar tanto asambleas y manifestaciones como protestas ante desahucios de viviendas

En este contexto de innovación en los medios ciudadanos no parece que «lo nuevo» implique necesariamente la desaparición de «los viejos medios». En el videoactivismo encontramos un ejemplo ilustrativo: nacen nuevos medios como Toma La Tele (www.tomalatele.tv) que se alían con proyectos de televisión ya existentes como La Tele de Barcelona (www.latele.cat) y TeleK en Madrid (www.vallecas.org). También se observa una tendencia hacia la convergencia de soportes como muestra la colaboración entre la radio surgida del 15M en Madrid (www.agorasolradio.org) y la televisión local Canal33 (www.canal33.info).

\section{Las transformaciones de Internet en la radio comunitaria}

\subsection{Evolución en el uso de Internet}

El nuevo impulso que toma el movimiento de radios libres y comunitarias durante los 2000 no se entiende sin el impulso del movimiento alterglobalización y el rol de las nuevas tecnologías en éste. Muchas voces auguraban que Internet sería el final de las radios libres y comunitarias, pero Internet se convierte en aliada de estas radios.

Concretamente, Internet va a propiciar el desarrollo de proyectos informativos para distribución en red entre las radios libres y comunitarias del estado, contribuyendo al desarrollo de una nueva fase de coordinación.

Las radios han ido incorporando de forma progresiva y precaria el uso de las nuevas tecnologías. El primer paso fue incluir a finales de los 90 el uso de ordenadores que resultaban muy útiles para la grabación de cuñas y la emisión 
de continuidad (24/7), en muchos casos se trataba de ordenadores donados o reciclados.

En el año 2000 la mayor parte de radios contaban con página web pero eran escasas las que contaban con conexión a Internet de banda ancha en su local.

En la siguiente tabla mostramos como se han ido incorporando al uso de Internet mostrando el momento en el que se comienza a generalizar el uso distintas tecnologías.

Tabla 3: Usos de Internet en las radios comunitarias.

\begin{tabular}{|l|l|}
\hline 2001 & $\begin{array}{l}\text { Emisión online mediante streaming de audio } \\
\text { Creación de sus propias Agencias de Noticias por Internet } \\
\text { (www.kaosenlared.net, www.ania.urcm.net) }\end{array}$ \\
\hline 2002 & $\begin{array}{l}\text { Intercambio de programas de radio via FTP } \\
\text { Emisión en cadena de programa informativo «Red Con Voż }\end{array}$ \\
\hline 2006 & $\begin{array}{l}\text { Intercambio y difusión de programas mediante podcasting } \\
\text { Se crea un servicio de podcasting propio www.audio.ucm.net }\end{array}$ \\
\hline 2008 & $\begin{array}{l}\text { Comienzo de las emisiones en cadena para retransmisión de programas especial } \\
\text { (cobertura manifestaciones o foros sociales). }\end{array}$ \\
\hline 2010 & $\begin{array}{l}\text { Las radios comunitarias comienzan a usar Facebook y Twitter } \\
\text { www.AgoraSolradio.org www.TomalaTele.tv } \\
\text { Se intensifican las emisiones en cadena }\end{array}$ \\
\hline 2012 & $\begin{array}{l}\text { Campañas de Crowdfunding a través de Internet } \\
\text { Desarrollo de aplicaciones para teléfonos móviles (Smartphone app). }\end{array}$ \\
\hline
\end{tabular}

\subsection{Radio FM vs. Radio Internet}

Las dificultades para emitir por FM o para logran tener una amplia cobertura han dificultado enormemente el desarrollo de las radios comunitarias, que además se exponen a cierres o elevadas multas. La proliferación de emisoras han convertido el dial de las grandes ciudades en una autentica selva dejando a muchas emisoras sin espacio para emitir.

Ante esta situación algunas radios no lucrativas han sustituido la FM por Internet, es el caso de las radios escolares que tras comprobar la imposibilidad de acceder a un permiso legal optan por emitir por Internet. Pero en el caso de las radios libres y comunitarias no se ha dado esta migración sino un uso simultáneo donde Internet supone un complemento y una garantía de continuidad a los proyectos. Para estas radios es importante seguir emitiendo en FM, no por nostalgia, sino porque mantienen vivas su reivindicaciones históricas, el derecho a emitir y a tener un espacio en el dial.

A continuación se muestra una tabla en la que se recogen los proyectos existentes en cada CCAA y su tipo de transmisión. Se recogen proyectos que encajan con la 
definición de radio comunitaria expuesta en el apartadodos del presente texto, es decir proyectos gestionados por una entidad privada (colectivo de personas) que producen y administran sus propios contenidos sus propios contenidos. Por lo tanto se han excluido proyectos individuales, canales musicales temáticos o agregadores de podcast.

Tabla 4: estimación de emisoras comunitarias existentes en FM e Internet

\begin{tabular}{|c|c|c|c|}
\hline Comunidad Autónoma & $\begin{array}{l}\text { Emisión en FM y } \\
\text { simuleast }\end{array}$ & Sólo Internet & Coordinadoras de radios \\
\hline Andalucia & 9 & $\mathrm{~s} / \mathrm{i}$ & \\
\hline Aragón & 6 & $s / 1$ & $\begin{array}{l}\text { Federación Aragonesa de } \\
\text { Radios Libres }\end{array}$ \\
\hline Asturias & 5 & $s / i$ & \\
\hline Baleares & 1 & 1 & \\
\hline Canarias & 6 & $s / 1$ & \\
\hline Cantabria & $\mathrm{s} / \mathrm{i}$ & $\mathrm{s} / \mathrm{i}$ & \\
\hline Castilla La Mancha & 5 & $\mathrm{~s} / \mathrm{i}$ & \\
\hline Castilla y León & 10 & $\mathrm{~s} / \mathrm{i}$ & \\
\hline Cataluña & 13 & 1 & $\begin{array}{l}\text { Coordinadora Ràdios Lliures } \\
\text { de Catalunya } \\
\text { http://radioslliures.info/ }\end{array}$ \\
\hline Extremadura & $\mathrm{s} / \mathrm{i}$ & $\mathrm{s} / \mathrm{i}$ & \\
\hline Galicia & 7 & $8 / i$ & $\begin{array}{l}\text { Rede galega de Radios Libres } \\
\text { e comunitarias Regarlic } \\
\text { www corme net/regarlic. }\end{array}$ \\
\hline La Rioja & $\mathrm{s} / \mathrm{i}$ & $\mathrm{s} / \mathrm{i}$ & \\
\hline Madrid & 15 & 4 & $\begin{array}{l}\text { Unión de Radios Libres y } \\
\text { Comunitarias de Madrid } \\
\text { www.urcm.net }\end{array}$ \\
\hline Murcia & 3 & 1 & \\
\hline Navarra & 2 & $\mathrm{~s} / \mathrm{i}$ & \\
\hline Pais Vasco & 11 & $\mathrm{~s} / \mathrm{i}$ & \\
\hline Valencia & 8 & 1 & $\begin{array}{l}\text { Xarra Radios Lliures del Pais } \\
\text { Valencia }\end{array}$ \\
\hline Ceuta & $\mathrm{s} / \mathrm{i}$ & $\mathrm{s} / 1$ & \\
\hline Melilla & $\mathrm{s} / \mathrm{i}$ & $\mathrm{s} / \mathrm{i}$ & \\
\hline Total & 101 & 8 & \\
\hline
\end{tabular}

Fuente: elaboración propia con datos de la Red de Medios Comunitarios

Los datos muestran que internet no se ha convertido en un sustituto de la FM en el sector de las radios libres y comunitarias. La mayor parte de estas radios apuestan por la emisión simultanea en FM y a través de internet (online y a la carta) siendo una minoría las emisoras que emiten exclusivamente por internet, aunque su cifra va en aumento. Estos resultados se deben en gran medida a la antigüedad de los proyectos, más de $50 \%$ de los incluidos en la tabla supera los 20 años de historia. Entre las radios de reciente creación nos encontramos tanto con proyectos que optan sólo por internet, como Ágora Sol Radio (www. agorasolradio.org) o Xaman Radio (www.radioxaman) en Madrid, como con emisoras que apuestan principalmente por la emisión en FM como el caso de Radio Almaina de Granada (www.radioalmaina.org). 
También nos encontramos con casos de radios históricas, como Radio Pica de Barcelona (www.radiopica.net) o Radio Carcoma en Madrid (www.radiocarcoma.net) que han abandonado la emisión en FM por dificultades económicas o por dificultades para instalar la antena. Una tendencia a contracorriente frente al progresivo desplazamiento de las audiencias de los medios tradicionales hacia Internet, especialmente en la población más joven. Pero en el caso particular de las radios comunitarias hay otros factores a considerar como la posibilidad de contar con una buena ubicación para la antena o encontrarse en una localidad donde no existan huecos en el dial. Así para algunos resulta más directo y fácil acceder a mayores audiencias mediante medios tradicionales como la FM que por Internet. Optar por la emisión simultánea por FM y por Internet hasta el momento parece haber sido una estrategia efectiva.

\subsection{Las radios comunitarias en las redes sociales}

Quizá un dato más preocupante tiene que ver con el uso y presencia de las radios comunitarias en las redes sociales, en especial Facebook y Twitter. Su incorporación a estas redes ha sido tardía. Muchos de los perfiles analizados presentan escasa o irregular actividad y no cuentan con grandes cifras de seguimiento. Más de un $60 \%$ de los proyectos cuentan con perfil propio en Twitter, Facebook o en ambas, pero llama la atención que muchos de los perfiles, especialmente en Twitter, se han creado durante 2011. Parece que muchas radios no se han convencido del potencial de las redes sociales hasta el surgimiento del movimiento $15 \mathrm{M}$.

A 7 de enero de 2013 las radios con mayor popularidad en Facebook son Radio Guiniguada (Canarias) con 4.231 amigos y Tas-Tas Irratia (Bilbao) con 5.190 amigos. En Twitter@AgoraSolRadio tiene66.574 seguidores y @RadioKlara tiene 4.699, otras rondan los tres mil seguidores, pero la gran mayoría de las radios no supera los 1.000 seguidores. En comparación con otros medios alternativos las radios tienen poca visibilidad en los nuevos espacios digitales, hitos como las coberturas realizadas conjuntamente por las radios durante las jornadas de huelga general o en otras movilizaciones han tenido una repercusión muy limitada en las redes sociales.

\section{Conclusiones}

Las radios libres y comunitarias fueron pioneras y adelantaron formas de comunicación y participación ciudadana que ahora con Internet resultan naturales; apropiación de las tecnología, periodismo ciudadano, funcionamiento horizontal. Ahora en comparación con las nuevas tecnologías han quedado obsoletas, pero siguen siendo herramientas muy valiosas para el activismo social especialmente en el ámbito local donde se han configurado como espacios que dinamizan la participación ciudadana. 
El reparto del dial a medios gubernamentales y comerciales ha relegado a estas emisoras a una presencia marginal en el dial (pocas, pequeñas y precarias). Y cada vez van a tener más dificultades para emitir, bien por la falta de espacio en el dial o por la aplicación de regulaciones restrictivas que limiten su cobertura

La problemática legal de las radios sin ánimo de lucro en España es reflejo de un déficit democrático que va más allá de la existencia de restricciones a la libertad de expresión. Un verdadero reconocimiento y desarrollo del Tercer Sector Audiovisual no será posible si no hay cambios estructurales a nivel de la administración estatal y autonómica.

Debido a las barreras de acceso a los medios y soportes tradicionales (radio, prensa, televisión) Internet ha pasado a ser el principal soporte de los medios ciudadanos. Sin embargo, a medio plazo esto no va a significar la desaparición de las radios libres y comunitarias ni el abandono de la radio FM. Estas emisoras, al igual que las televisiones comunitarias, siguen reclamando el acceso de la ciudadanía al espectro radioeléctrico para crear sus propios medios. Su continuidad en el dial (tomar las ondas) es una forma de resistencia que tienen que ver con las tensiones respecto de los usos y titularidad de los recurso naturales y los bienes comunes. El espectro radioeléctrico es un dominio público, un patrimonio de la humanidad que está siendo acaparado por grandes grupos mediáticos y por los operadores de telecomunicaciones (telefonía e internet móvil).

Esta demanda histórica se ha ido abandonando por la idea de que ya no necesitamos el dial porque tenemos Internet. Ciertamente Internet ha posibilitado la creación de nuestros propios medios sin limitación de número y cobertura, pero no es una solución mágica que garantice el acceso a grandes audiencias para dejar de ser un medio minoritario ni tampoco resuelve viejos problemas como la censura o nuevas formas de control social. En el espacio virtual tenemos derecho de uso y disfrute pero no sobre la propiedad o gestión del soporte.

Así las cosas estamos en una etapa donde se está reconfigurando el Tercer Sector Audiovisual. Cada vez su configuración es más compleja y más multimedia. Con Internet ha aumentado el número de medios existentes pero también su fragmentación (muchos, pequeños y precarios) lo que no impide que en momentos cruciales, como los que están por llegar, este caótico sistema mediático ciudadano pueda tener un papel muy relevante.

\section{Referencias}

Amarc (2010). Principios para garantizar la diversidad y el pluralismo en la radiodifusión y los servicios de comunicación audiovisual. Buenos Aires: Fundación Ford.

Bassets, Lluís (ed.) (1981): De las ondas rojas a las radios libres. Barcelona: Gustavo Gili. 
Calle, Ángel (2005): Nuevos movimientos globales. Hacia la radicalidad democrática. Madrid: Popular.

Downing, John (2009). «Nanomedios de comunicación. ¿O dered? ¿O demovimientos sociales? ¿Quéimportanciatienen? ¿Y su denominación?»Universidad Autónoma de Barcelona: Cátedra UNESCO de ComunicacióN InCom-UAB. Disponible en: http://www.portalcomunicacion.com/catunesco/download/2010_DOWNING_ NANOMEDIOS\%20DE\%20COMUNICACI\%C3\%93N.pdf (03/01/2013).

Lewis, Peter (2008). Promoting Social Cohesion: the role of community media. Informe para el Consejo de Europa. Disponible en: http://www.coe.int/t/dghl/ standardsetting/media/doc/H-Inf\%282008\%29013_en.pdf (03/01/2013)

Martínez, Miguel (1998): «Islas de autogestión en un mar de contradicciones. Cuatro movimientos sociales alternativos en el estado español (1978-1998)». En: Hartza, septiembre. Disponible en: http://www.hartza.com/cabuenes.htm (01/12/2012).

Meda, Miriam (2010): «La Ley UTECA y el Tercer Sector de la Comunicación: comparativa internacional de las fallas de la legislación española audiovisual y respuesta de la sociedad civil». Tesis de Maestría. Disponible en: http://medagonzalez.es/text/ley_uteca_y_tercer_sector.pdf (03/01/2013).

MITYC (2010). «Anteproyecto del Reglamento de Servicios de Comunicación Comunitarios. Presentado el 25 de noviembre de 2010 en el Consejo Asesor de las Telecomunicaciones y para la Sociedad de la Información». Disponible en: http://legal.medioscomunitarios.net/wp-content/uploads/2010/12/reglamentotecnico-catsi1.doc (03/01/2013).

Moragas, Miguel de (1988): Espais de Comunicació: experiéncies i perspectives a Catalunya. Barcelona: Edicions 62.

Prado, Emili (1981): El movimiento por la libertad de emisión en España. En: Bassets, Lluís (ed.). De las ondas rojas a las radios libres. Barcelona: Gustavo Gilli, 237 - 255.

Serrano, J. (a.k.a. Virus) (1994): "Radios Libres... toda una historia por delante”. ZGZ Rebelde. Disponible en: http://www.zaragozarebelde.org/historia_radios_libres (03/01/2013).

ULEPICC (2009). «Proyecto de Ley General de la Comunicación Audiovisual. Reforma y contrarreforma en la política de comunicación audiovisual del Gobierno de Rodríguez Zapatero». Declaración pública, 28 de noviembre de 2009. Disponible en http://www.ulepicc.es/web/documentos/DeclaracionULEPICC.pdf (03/01/2013).

Zallo, Ramón (2010): La política de Comunicación Audiovisual del gobierno socialista (2004-2009): un giro neoliberal. En: Revista Latina de Comunicación Social, $\mathrm{n}^{0}$ 65. La Laguna (Tenerife): Universidad de La Laguna, 14-29. Disponible en: http://www.revistalatinacs.org/10/art/880_UPV/02_Zallo.html (03/01/2013). DOI: 10.4185/RLCS-65-2010-880-014-029. 


\subsection{Referencias legales}

BOCG (1987a). «Proyecto de Ley 121/000029 de Ordenación de las Telecomunicaciones». Boletín Oficial de las Cortes Generales (Congreso de los Diputados), $n^{0}$ 27-1 (21/03/1987). Disponible en: http://www.congreso.es/public_oficiales/ L3/CONG/BOCG/A/A_027-01.PDF (03/06/2011).

BOCG (1987b). «Proyecto de Ley de Ordenación de las Telecomunicaciones». Boletín Oficial de las Cortes Generales (Senado), no ${ }^{0} 29(\mathrm{c})$ (23/11/1987). Disponible en http://www.congreso.es/public_oficiales/L3/SEN/BOCG/II/II0129C. PDF (03/06/2011).

BOCG (1987c). «Sesión Plenaria $n^{0} .76$ celebrada el miércoles, 16 de diciembre de 1987». Boletín Oficial de las Cortes Generales (Congreso), $\mathrm{n}^{\mathrm{o}}$ 78, (16/12/1987). Disponible en: http://www.congreso.es/public_oficiales/L3/ CONG/DS/PL/PL_078.PDF (03/06/2011).

BOCG (1998): «Preguntas para respuesta escrita (184/014332): Previsión por parte del Gobierno para regular la asignación de algunas frecuencias en el plan técnico de radiodifusión sonora de frecuencia modulada para las emisoras privadas de carácter asociativo, comunitarias o culturales». Boletín Oficial de las Cortes Generales (Congreso de los Diputados) VI Legislatura, $\mathrm{n}^{\circ}$ 261 (02/04/1998). Disponible en: http:/www.congreso.es/public_oficiales/L6/ CONG/BOCG/D/D_261.PDF (03/06/2011).

BOCG (2007): «Preguntas para respuesta escrita (184/115134): Opinión del Gobierno acerca de si las Comunidades Autónomas podrían destinar parte de las frecuencias de gestión indirecta que recoge el Plan Técnico a entidades sin ánimo de lucro y así dar respuesta a la demanda de emisoras comunitarias y asociativas». Boletín Oficial de las Cortes Generales (Congreso de los Diputados) VIII Legislatura, $\mathrm{n}^{\mathrm{o}} 553$ (17/05/2007). Disponible en: http://www.congreso.es/ public_oficiales/L8/CONG/BOCG/D/D_553.PDF (03/06/2011).

BOE (1979): «Real Decreto 1433/1979, de 8 de junio, por el que se establece el Plan Técnico Transitorio del Servicio Público de Radiodifusión Sonora en ondas métricas con modulación de frecuencia». Boletín Oficial del Estado, $\mathrm{n}^{\mathrm{o}}$ 145 (18/6/1979). Disponible en: http://www.boe.es/boe/dias/1979/06/18/pdfs/ A13500-13501.pdf (03/06/2011).

BOE (1987a): «Resolución de 21 de julio de 1987, de la Dirección General de Telecomunicaciones, por la que se establece el plan de asignaciones de frecuencia a estaciones de radiodifusión sonora en ondas métricas con modulación de frecuencia que funcionan en la banda de frecuencias de 87,5 MHZ a $108 \mathrm{MHZ}$ ». Boletín Oficial del Estado, n ${ }^{\circ} 243$ (10/10/1987). Disponible en: http://www.boe. es/boe/dias/1987/10/10/pdfs/A30484-30490.pdf (03/06/2011).

BOE (1987b): «Ley 31/1987, de 18 de diciembre, de Ordenación de las Telecomunicaciones». Boletín Oficial del Estado, $\mathrm{n}^{\circ} 303$ (19/12/1987). Disponible en: http://www.boe.es/boe/dias/1987/12/19/pdfs/A37409-37419.pdf (03/06/2011). 
BOE (2010): «Ley 7/2010, de 31 de marzo, General de la Comunicación Audiovisual». Boletín Oficial del Estado, no 79 (01/04/201). Disponible en: http://boe. es/boe/dias/2010/04/01/pdfs/BOE-A-2010-5292.pdf (03/06/2010).

DOGV (1989): «Resolució 613 de 14 de març de 1989, del Subsecretari Director del Gabinet del President de la Generalitat Valenciana, per la qual es convoca concurs públic per a la concessió de 28 emissores en ones mètriques amb modulació de freqüència a la Comunitat Valenciana». Diario Oficial de la Comunidad Valenciana 20/03/1989). Disponible en: http://www.docv.gva.es/ datos/1989/03/20/pdf/dogv_1029.pdf (03/06/2011).

\section{Referencia de este artículo}

García García, Javier (2013). Transformaciones en el Tercer Sector: el caso de las radios comunitarias en España. En: adComunica. Revista Científica de Estrategias, Tendencias e Innovación en Comunicación, $n^{\circ} 5$. Castellón: Asociación para el Desarrollo de la Comunicación adComunica, Universidad Complutense de Madrid y Universitat Jaume I, 111-131. DOI: http://dx.doi.org/10.6035/21740992.2013.5.8 